\title{
Porous GaP Multilayers Formed by Electrochemical Etching
}

\author{
R. W. Tjerkstra, ${ }^{\mathrm{a}, \mathrm{c}}$ J. Gómez Rivas, ${ }^{\mathrm{b}}$ D. Vanmaekelbergh, ${ }^{\mathrm{a}}$ and J. J. Kelly ${ }^{\mathrm{a}, *, \mathrm{z}}$ \\ ${ }^{a}$ Debye Institute, Utrecht University, 3508 TA Utrecht, The Netherlands \\ ${ }^{b}$ Van der Waals Zeeman-Instituut, University of Amsterdam, 1018 XE Amsterdam, The Netherlands
}

The properties of porous $\mathrm{GaP}$, formed by anodic etching in $\mathrm{H}_{2} \mathrm{SO}_{4}$, are described. Pore size, pore density, and the interpore distance depend on the dopant density and the potential at which the sample is etched. In addition, it is shown that at high potential, the GaP passivates as a result of the formation of an oxide layer. These features allow us to grow multilayer structures of GaP with modulated porosity and/or oxide layers. The dissolution of oxide at the base of a porous layer can be used to produce freestanding porous membranes.

(C) 2002 The Electrochemical Society. [DOI: 10.1149/1.1466935] All rights reserved.

Manuscript submitted October 18, 2001; revised manuscript received January 25, 2002. Available electronically March 8, 2002.

There is currently a wide range of porous-etched semiconductors available with interesting physical and chemical properties. ${ }^{1}$ However, the field of application of porous semiconductors is still dominated by silicon. ${ }^{2}$ This material plays an important role in many technologies, including microelectromechanical systems (MEMS), ${ }^{3}$ optical and photonic devices, ${ }^{4,5}$ sensors, ${ }^{6}$ and (bio)chemical reactors. ${ }^{7}$ The success of silicon can be attributed to a large extent to the versatility of the etching process. ${ }^{8}$ Both p-type and n-type silicon can be made porous, and the porosity can be controlled within wide limits. ${ }^{8,9}$ As a result, modulated structures having, for example, a modulated refractive index, can be made for optical systems. ${ }^{10,11}$ Ordered networks of etched macropores find application in two- and three-dimensional photonic bandgap materials. ${ }^{12-14}$ Freestanding membranes can be formed by releasing the porous layer from the substrate by electrochemical polishing. ${ }^{3}$ Such samples can be used as sieves for, for example, biomolecules in micrototal analysis systems. ${ }^{15}$

In this paper, we show that a number of these etching features can also be realized in another semiconductor, GaP. There are various reasons to consider alternatives to porous silicon. Silicon has a large refractive index (3.5), and a bandgap of $1.1 \mathrm{eV}$. ${ }^{16}$ This makes macroporous silicon suitable for photonic applications in the nearinfrared region. ${ }^{17,18}$ Because of its indirect bandgap, macroporous silicon, like bulk silicon, shows only very weak luminescence (in the near infrared). The strong visible luminescence from microporous silicon due to size quantization has found application in sensors. ${ }^{6,19,20}$ The emission spectrum of porous silicon is broad and markedly dependent on the method of formation and the history of the sample. Gallium phosphide also has a large refractive index (3.2). However, its bandgap of $2.24 \mathrm{eV},{ }^{16}$ makes macroporous $\mathrm{GaP}$ an interesting photonic material for the visible spectral range. Porous $\mathrm{GaP}$, produced by anodic etching, is the most strongly scattering material for visible light, reported to date ${ }^{21}$ there is evidence for the onset of Anderson light localization ${ }^{22}$ in this material. At low temperature, bulk GaP shows a sharp luminescence emission centered at around $560 \mathrm{~nm}$ which is quenched at room temperature, ${ }^{23}$ macroporous GaP shows similar luminescent properties. ${ }^{23}$ Doping the bulk semiconductor isoelectronically with nitrogen gives efficient near band-band luminescence at room temperature. ${ }^{24}$ Similar results are expected for macroporous $\mathrm{GaP}$. This emission combined with the large surface area of the macroporous semiconductor and a surface chemistry quite different from that of silicon makes $\mathrm{GaP}$ interesting for sensor applications. Finally, the different surface chemistry may offer new and interesting possibilities in separation and reactor technologies.

Various n-type compound semiconductors can be made porous

\footnotetext{
* Electrochemical Society Active Member.

${ }^{\mathrm{c}}$ Present address: MESA ${ }^{+}$Institute, University of Twente, 7500 AE Enschede, The Netherlands.

zE-mail: j.j.kelly@phys.uu.nl
}

by electrochemical etching. ${ }^{1,25-27}$ Since valence band holes are required for the anodic oxidation, n-type electrodes do not etch under "normal" depletion conditions. However, at strongly positive potentials, when the band bending exceeds the bandgap of the solid, electrons may tunnel from the top of the valence band or from bandgap states to the conduction band. The resulting holes cause dissolution of the solid. The rate of this process is determined by the tunnel distance which depends on the width of the depletion layer; this is inversely proportional to the square root of the doping density. ${ }^{28}$ In addition, tunneling is sensitive to the state of the surface, e.g., to crystallographic defects and surface impurities. Consequently, anodic etching of n-type semiconductors under "breakdown" conditions is strongly localized, giving rise to porous structures. This is in contrast to the uniform dissolution which is usually observed with p-type material.

Two groups have recently studied the porous etching of n-type GaP. Karavanskii and co-workers ${ }^{29,30}$ produced micrometer thick light-yellow layers on (100) material by galvanostatic etching in a $50 \%$ solution of HF in ethanol. Erné et al. ${ }^{28,31}$ etched (100) wafers at constant potential $(5-15 \mathrm{~V})$ in aqueous $0.5 \mathrm{M} \mathrm{H}_{2} \mathrm{SO}_{4}$ solution, producing pores and pore walls with dimensions of about $100 \mathrm{~nm}$. The dependence of the morphology on the electrode material and the etching conditions were not considered in either study.

In the present work, we investigated the influence of the applied potential and dopant density on the anodic etching of $\mathrm{GaP}$. We first describe the experimental setup and the electrochemical results. We then show that anodic etching can be used to control the morphology of the porous layer, and we describe two approaches to obtaining modulated structures.

\section{Experimental}

For the experiments, n-type GaP single-crystal wafers, $300 \mu \mathrm{m}$ thick, with a (100) surface orientation were used. The four wafer types had dopant densities ranging from $4-5 \times 10^{17}$ to $10-20$ $\times 10^{17} \mathrm{~cm}^{-3}$. The samples were glued to a copper plate with silver epoxy, and covered with a Teflon sticker. A circular hole in this sticker left an area of $0.24 \mathrm{~cm}^{2}$ exposed to the electrolyte. The copper plate was also covered with Teflon, to prevent the copper from contacting the solution.

Etching experiments were performed in aqueous $0.5 \mathrm{M} \mathrm{H}_{2} \mathrm{SO}_{4}$ solution in the dark in a conventional three-electrode cell with a platinum counter electrode and a saturated calomel electrode (SCE) as reference. All potentials are given with respect to SCE. The equipment used for the experiments was an EG\&G PAR 273A potentiostat connected to a PC, and controlled with home-made software. To reach potentials above $10 \mathrm{~V}$, one or more $9 \mathrm{~V}$ batteries were used. After etching, the samples were examined using a Philips XL 30 field emission gun scanning electron microscope (FEGSEM) (Fig. 1a, 2, and 3), an ISI DS-130 SEM (Fig. 1b), or a Leo 1550 FEGSEM (Fig. 4). 

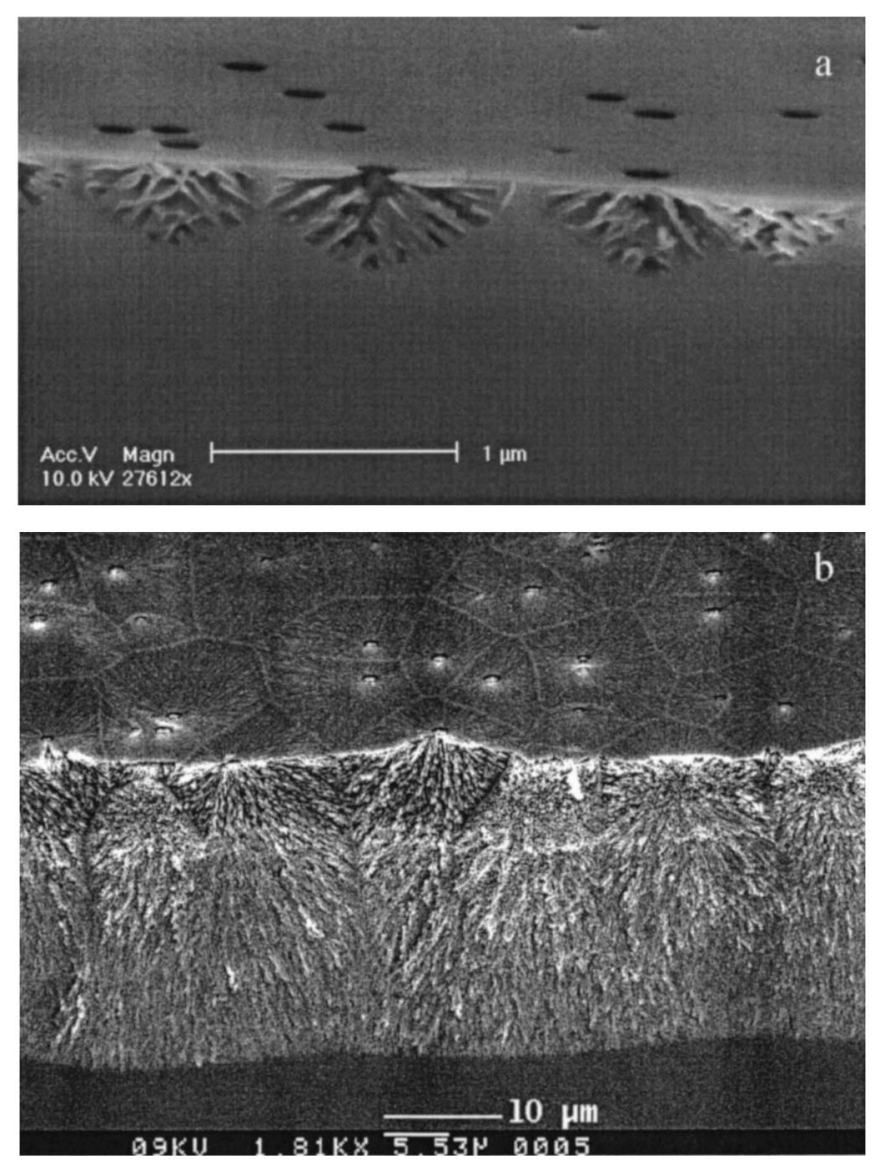

Figure 1. Porous regions in GaP, obtained (a) just after the etching started, and (b) after a steady-state current was reached.

\section{Results and Discussion}

Figure 5 shows the current density, $i$, as a function of the applied potential, $V$, for an n-type $\mathrm{GaP}$ electrode (dopant density 6 $\left.\times 10^{17} / \mathrm{cm}^{3}\right)$. The potential was scanned from $-1 \mathrm{~V}$, at a rate of 50 $\mathrm{mV} / \mathrm{s}$. Three distinctive regions are indicated in Fig. 5. At low potentials, the band bending is too small to allow interband tunneling. The semiconductor behaves as a reverse-biased diode, and the cur-

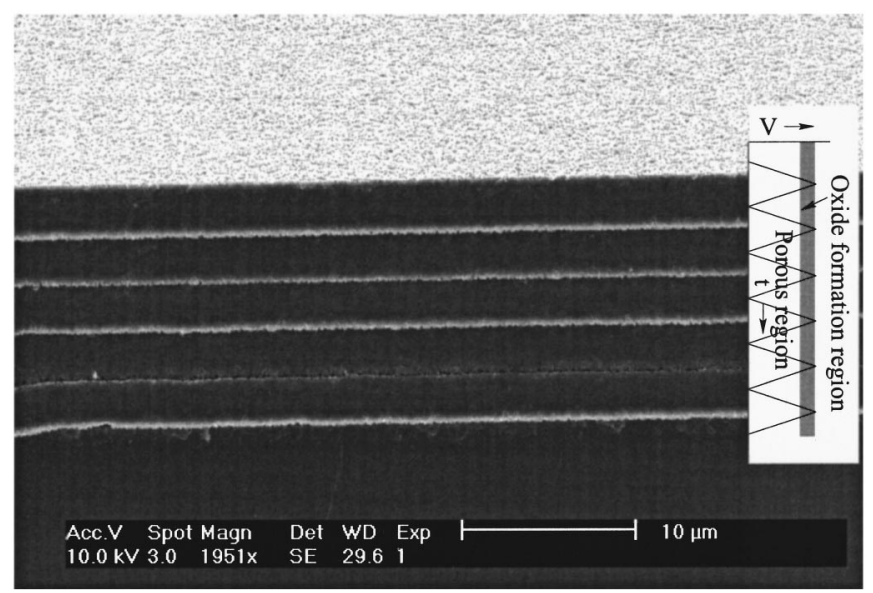

Figure 2. Porous GaP multilayer, made in a wafer with a dopant density of $6 \times 10^{17} / \mathrm{cm}^{3}$, by scanning the potential six times between -1 and $19 \mathrm{~V}$ (scan rate $50 \mathrm{mV} / \mathrm{s}$ ). The scanning cycle is indicated at the edge of the picture.

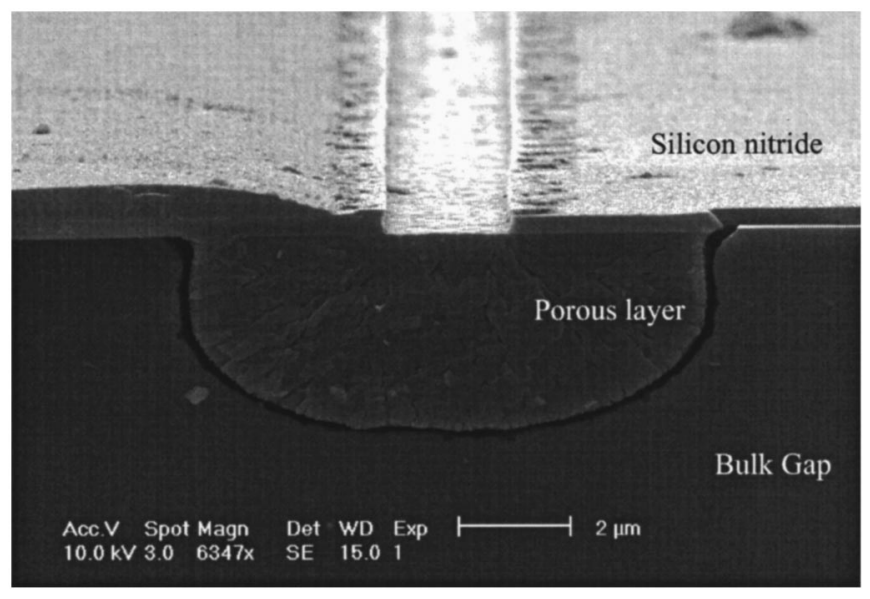

Figure 3. Freestanding layer of porous $\mathrm{GaP}$ in a wafer with dopant density of $8 \times 10^{17} / \mathrm{cm}^{3}$ masked with silicon nitride. The layer was formed by first etching in the porous range of the $\mathrm{i}-\mathrm{V}$ curve $(10 \mathrm{~V}$ for $10 \mathrm{~min})$, followed by etching in the passive range ( $15.5 \mathrm{~V}$ for $15 \mathrm{~min})$, after which the passivating oxide layer was allowed to dissolve at open circuit potential for $20 \mathrm{~min}$.
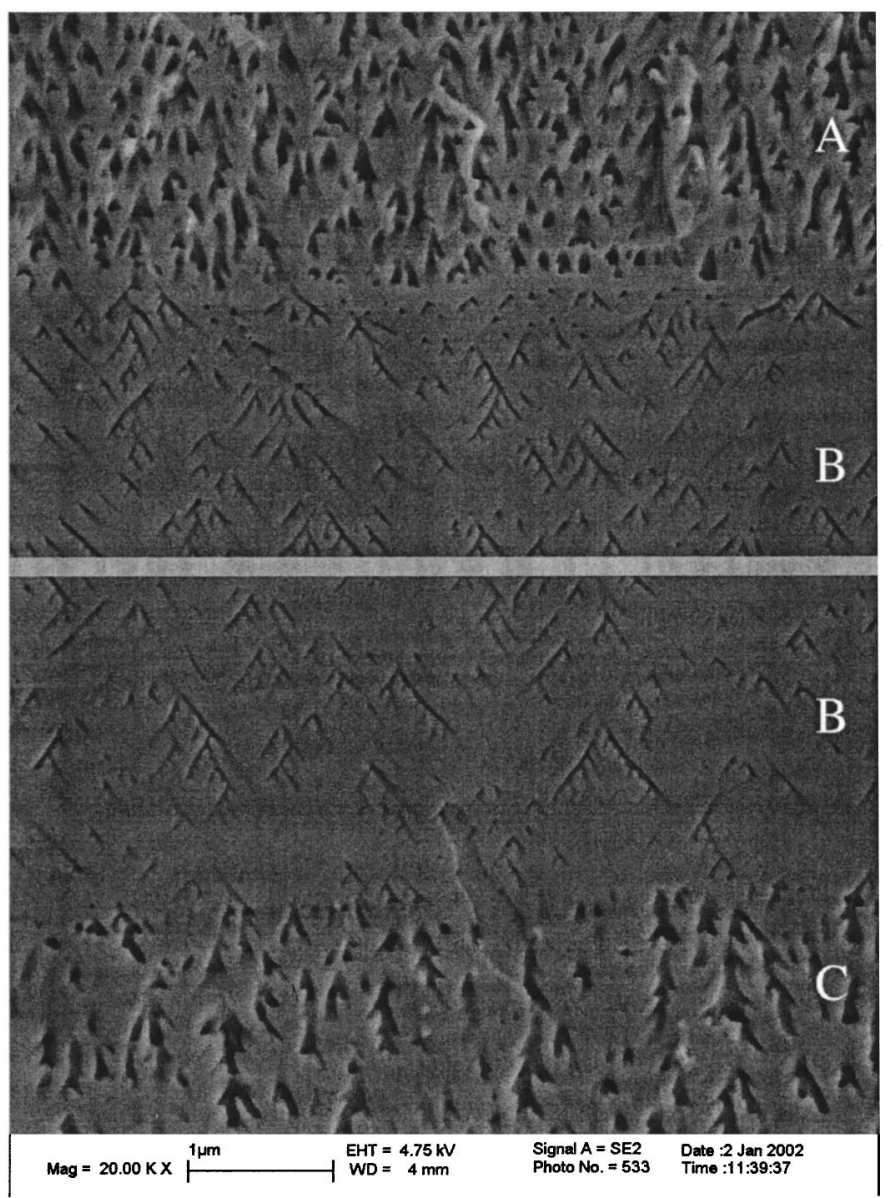

Figure 4. SEMs of two areas of a cross section of a GaP multilayer, made in a wafer with a dopant density of $6 \times 10^{17} / \mathrm{cm}^{3}$. Three layers with different porosities were etched at potentials of $11.4 \mathrm{~V}$ (layer A), $7.0 \mathrm{~V}$ (layer B), and $10 \mathrm{~V}$ (layer C). The two SEM pictures were taken at exactly the same magnification. 


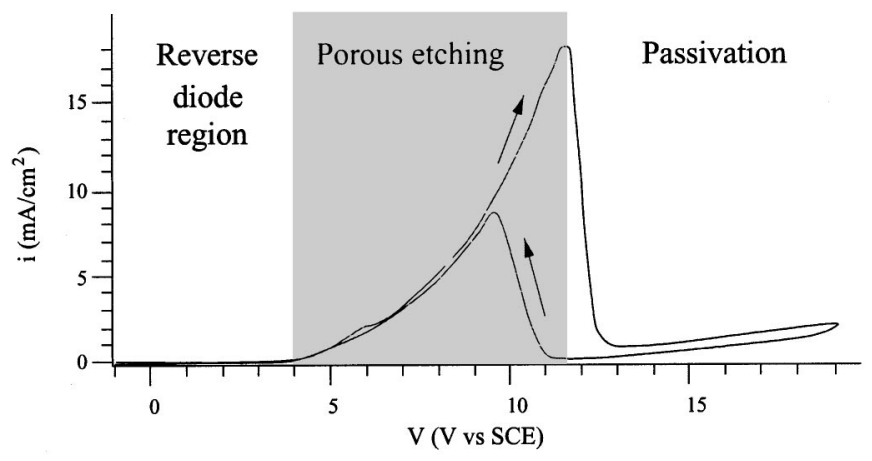

Figure 5. Typical i-V plot of an n-type GaP electrode (dopant density 6 $\times 10^{17} / \mathrm{cm}^{3}$ ) in a $0.5 \mathrm{M} \mathrm{H}_{2} \mathrm{SO}_{4}$ solution. Scan rate $50 \mathrm{mV} / \mathrm{s}$. The scan direction is indicated by arrows.

rent is almost zero. Above the breakdown potential (about $3 \mathrm{~V}$ in this case), an anodic current begins to flow and the current increases markedly as the potential is raised. This is the range in which porous etching was previously reported. ${ }^{19,20,28}$ At a more positive potential, a current maximum is observed after which the current decreases rapidly to a low value which shows only a weak potential dependence. Such current/potential (I-E) characteristics, which are typical of electrode passivation due to oxide formation, have not been reported before for n-type $\mathrm{GaP}$. In the reverse scan from $19 \mathrm{~V}$, a peak is also observed in the $\mathrm{i}-\mathrm{V}$ curve, but the current maximum is lower and occurs at a more negative potential. To observe current, the passive layer that has formed on the active $\mathrm{GaP}$ surface (the pore fronts) at potentials higher than the peak potential must first be removed. Oxide dissolution occurs via a slow chemical reaction; this accounts for the marked hysteresis observed in Fig. 5. At lower scan rates, which allow more time for the dissolution of the passive layer, the current peak in the return scan occurs at more positive potentials. The peak potential for the forward scan was found to depend on the dopant concentration, and varied from $20 \mathrm{~V}$ for the low-doped material to $7.5 \mathrm{~V}$ for the high-doped samples.

In Fig. 6, a current density/time (i-t) curve is shown of a sample etched at a fixed potential in the porous region. The etching starts at specific sites at the surface, as described by Erné et al. ${ }^{28}$ From these pits, isotropic porous domains develop, as shown in Fig. 1a. While the domains grow, the current density increases (Fig. 6). Eventually, the domains meet, the interface between the porous and the bulk $\mathrm{GaP}$ flattens out, and its total area decreases. Because etching only takes place at the porous $\mathrm{GaP} / \mathrm{bulk} \mathrm{GaP}$ interface, the current density, which is proportional to the total area of this interface, also decreases, until the interface becomes flat and a stationary current is reached (Fig. 6). In Fig. 1b, the separation between the porous domains is clearly visible in the upper part of the porous layer, while further in the bulk the domains blend together.

The morphology of the various porous wafers was investigated as a function of the potential. For a fixed dopant density it is clear that in the range marked porous etching in Fig. 5, the porosity is higher at more positive potentials. This was shown in an experiment in which the potential of the electrode (dopant density 6 $\times 10^{17} / \mathrm{cm}^{3}$ ) was first held at $11.4 \mathrm{~V}$ (case A), then lowered to $7 \mathrm{~V}$ (case $\mathrm{B}$ ), and finally raised to $10 \mathrm{~V}$ (case $\mathrm{C}$ ). The charge densities passed through the sample were 21,16 , and $9.6 \mathrm{C} / \mathrm{cm}^{2}$, respectively. From a low-resolution scanning electron microscope (SEM) picture of a cross section of the cleaved sample (not shown) it was clear that three porous layers were formed with thicknesses of $37 \mu \mathrm{m}$ (layer A), $69 \mu \mathrm{m}$ (layer B), and $13 \mu \mathrm{m}$ (layer C). Because six charge carriers are required to dissolve one $\mathrm{GaP}$ formula unit ${ }^{22}$ and no side reactions take place, the volume of $\mathrm{GaP}$ removed could be calculated from the charge passed through the sample during etching. Using this volume, and the thickness of the porous layer, we calculated porosities (the percentage of material removed during etching)

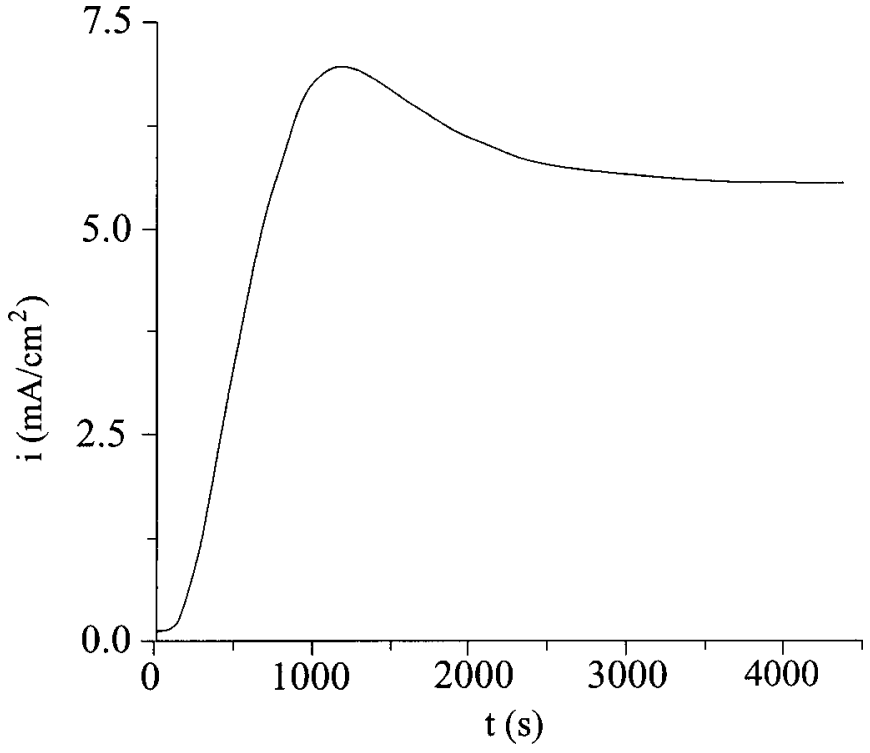

Figure 6. Typical i-t plot of an n-type $\mathrm{GaP}$ electrode (dopant density 6 $\times 10^{17} / \mathrm{cm}^{3}$, etching potential $11.4 \mathrm{~V}$ ) in a $0.5 \mathrm{M} \mathrm{H}_{2} \mathrm{SO}_{4}$ solution.

of 24,10 , and $31 \%$ for layers A, B, and C, respectively. The porosity of the bottom layer, $\mathrm{C}$, is higher than that of the top layer, $\mathrm{A}$, despite the lower etching potential of the bottom layer. In this case, the dissolution products must be removed through a thick $(69 \mu \mathrm{m})$ intermediate layer of $\mathrm{GaP}$ with a very low porosity (10\%). The etching conditions must therefore be somewhat different than in the case of layer A.

Figure 4 shows higher resolution SEM pictures of part of the cleaved cross section at the two interfaces between the porous layers. Average pore diameters were determined by considering the dimensions of ten pores on an enlarged SEM picture. The pore diameters in layer $\mathrm{A}(73 \pm 18 \mathrm{~nm})$ and $\mathrm{C}(81 \pm 22 \mathrm{~nm})$ are much larger than in layer B $(41 \pm 9.5 \mathrm{~nm})$. The pores in layer B also seem to be oriented along crystallographic axes. This phenomenon has also been observed by Stevens-Kalceff $e t a l{ }^{32}$ The results show that both the pore dimensions and the porosity can be controlled by the applied potential. In addition, the porosity of the etched wafers depends on the dopant density and the applied potential. Porosities as high as $66 \%$ were reached using a wafer with a dopant density of $10-20 \times 10^{17} \mathrm{~cm}^{-3}$ and a potential of $7.4 \mathrm{~V}$ (the peak potential of the current density/voltage (i-V) curve for this wafer).

Apart from the modulation of the porosity on the basis of the applied potential in the porous etching range, the $\mathrm{i}-\mathrm{V}$ characteristics of Fig. 5 suggest another approach for layer tuning. This method, which makes use of the oxide formation and dissolution in the passivation range, is illustrated with the examples in Fig. 2. This figure shows a SEM cross section of a wafer with a dopant density of 6 $\times 10^{17} / \mathrm{cm}^{3}$, which was subjected to six consecutive linear potential scans between -1 and $19 \mathrm{~V}$ at $50 \mathrm{mV} / \mathrm{s}$.

In this experiment, the electrode is passed back and forth between active and passive states. The oxide formed during a forward scan is removed in the reverse scan of each cycle. The SEM results show a multilayer structure which corresponds closely to the cycling sequence indicated at the edge of the picture. The period spent in the range of oxide formation is clearly evident in the transition region (white stripes) between the porous layers. The final layer, which corresponds to only half a cycle, has a thickness equal to half that of the other layers. This should also hold for the first layer, which, in fact, is missing. We suspect that the layer peeled off when the sample was cleaved. From the results of Fig. 4, one expects to see a gradation in porosity across each of the layers shown in Fig. 2, since the potential is continuously changed during the experiment. This is, 
indeed, clear from higher resolution SEM pictures (not shown).

By forming and dissolving an oxide layer after a period of porous etching we have been able to make freestanding membranes of porous $\mathrm{GaP}$ (see Fig. 3), like those previously reported for $\mathrm{Si}^{3}{ }^{3}$ The surface of a GaP wafer with a dopant density of $8 \times 10^{17} / \mathrm{cm}^{3}$ was provided with a silicon nitride mask containing an elongated rectangular opening. A porous layer was formed in the semiconductor by anodic etching (10 V for $10 \mathrm{~min}$ ) through the window in the mask. The layer, which grew isotropically, was approximately $3.5 \mu \mathrm{m}$ thick. In order to open a gap between the porous layer and the substrate, the potential was switched to the passive range ( $15.5 \mathrm{~V}$ for $15 \mathrm{~min}$ ) and subsequently to the open-circuit potential (for $20 \mathrm{~min}$ ). The width of the gap (130 nm in Fig. 3) can obviously be controlled by the etching period in the passive range.

\section{Conclusions}

In this work, we have shown that both the porosity and the pore size of porous $\mathrm{GaP}$ can be easily regulated by means of the potential applied during anodic etching of n-type material in a $0.5 \mathrm{M} \mathrm{H}_{2} \mathrm{SO}_{4}$ solution. This allows the fabrication of multilayer structures with modulated properties. In addition, an air gap can be introduced between porous layers giving an extra degree of freedom in multilayer applications. In particular, an air gap can be used as a channel between the porous layer and the crystalline substrate, thus forming freestanding $\mathrm{GaP}$ porous membranes. Such multilayers could find application in a wide range of fields, including micromechanics, and, optical, photonic, and sensor systems.

\section{Acknowledgment}

We thank Hewlett-Packard and Philips Research, Eindhoven, The Netherlands, for supplying us with wafers, S. Zevenhuizen, for writing special software for the potentiostat, and Professor X. Xia (UU), W. Takkenberg (UvA), and M. Smithers (UT) for assisting us in making the SEM pictures. Professor Xia is also acknowledged for fruitful discussions. This work was supported by the European Commission through grant no. ERBFM-BICT971921, and the Dutch Organization for Chemical Sciences CW. article.

The University of Utrecht assisted in meeting the publication costs of this

\section{References}

1. J. J. Kelly and D. Vanmaekelbergh, The Electrochemistry of Nanomaterials, G. Hodes, Editor, Chap. 4, Wiley-VCH, Weinheim, Germany (2001).
2. See, for example, J. Porous Mater, 7, 1 (2000).

3. R. W. Tjerkstra, J. G. E. Gardeniers, J. J. Kelly, and A. van den Berg, J. Microelectromech. Syst., 9, 495 (2000).

4. A. Loni, L. T. Canham, M. G. Berger, R. Arens-Fischer, H. Münder, H. Lüth, H. F. Arrand, and T. M. Benson, Thin Solid Films, 276, 143 (1996).

5. S. Setzu, P. Ferrand, and R. Romestain, Mater. Sci. Eng., 69-70, 34 (2000).

6. S. E. Létant and M. J. Sailor, Adv. Mater, 355, 12 (2000).

7. J. Drott, K. Lindström, L. Rosengren, and T. Laurell, J. Micromech. Microeng., 7, 14 (1997).

8. M. I. J. Beale, J. D. Benjamin, M. J. Urem, N. G. Chew, and A. G. Cullis, J. Cryst. Growth, 73, 622 (1985).

9. R. Herino, G. Bomchil, K. Barla, C. Bertrand, and J. J. Ginoux, J. Electrochem. Soc., 143, 1994 (1987)

10. L. Pavesi and P. Dubos, Semicond. Sci. Technol., 12, 570 (1997).

11. H. A. Lopez and P. M. Fauchet, Appl. Phys. Lett., 77, 3704 (2000).

12. A. Chelnokov, K. Wang, S. Rowson, P. Garoche, and J.-M. Lourtioz, Appl. Phys. Lett., 77, 2943 (2000).

13. M. E. Zoorob, M. D. B. Charlton, G. J. Parker, J. J. Baumberg, and M. C. Netti, Nature, 404, 740 (2000)

14. J. Schilling, F. Müller, S. Matthias, R. B. Wehrspohn, U. Gösele, and K. Busch, Appl. Phys. Lett., 78, 1180 (2000)

15. A. van den Berg and T. S. J. Lammerink, Top. Curr. Chem., 194, 21 (1998).

16. Handbook of Chemistry and Physics, R. C. Weast, Editor, CRC Press, Boca Raton, FL (1989).

17. F. Müller, A. Birner, U. M. Gösele, V. Lehmann, S. Ottow, and H. Föll, J. Porous Mater., 7, 201 (2000).

18. A. Birner, R. B. Wehrspohn, U. M. Gösele, and K. Busch, Adv. Mater., 13, 377 (2001).

19. M. T. Kelly, J. K. M. Chun, and A. B. Bocarsly, Nature, 382, 214 (1996).

20. G. Di Francia, V. La Ferrara, L. Quercia, and G. Faglia, J. Porous Mater, 7, 287 (2000).

21. F. P. J. Schuurmans, D. Vanmaekelbergh, J. van de Lagemaat, and A. Lagendijk, Science, 284, 141 (1999).

22. F. P. J. Schuurmans, M. Megens, D. Vanmaekelbergh, and A. Lagendijk, Phys. Rev. Lett., 83, 2183 (1999).

23. A. Meijerink, A. A. Bol, and J. J. Kelly, Appl. Phys. Lett., 69, 2801 (1996).

24. W. O. Groves, A. H. Herzog, and M. G. Craford, Appl. Phys. Lett., 19, 184 (1971).

25. P. Schmuki, J. Fraser, C. M. Vitus, M. J. Graham, and H. S. Isaacs, J. Electrochem. Soc., 143, 3316 (1996).

26. S. Langa, I. M. Tiginyanu, J. Cartensen, M. Christophersen, and H. Föll, Electrochem. Solid-State Lett., 3, 514 (2000).

27. J. S. Shor, R. Grimberg, B.-Z. Weiss, and A. D. Kurtz, Appl. Phys. Lett., 62, 2836 (1993).

28. B. H. Erné, D. Vanmaekelbergh, and J. J. Kelly, J. Electrochem. Soc., 143, 305 (1996).

29. A. I. Belogorokov, V. A. Karavanskii, A. N. Obraztsov, and V. Yu. Timoshenko, JETP Lett., 60, 274 (1994).

30. A. Anedda, A. Serpi, V. A. Karavanskii, I. N. Tiginyanu, and M. V. Ichizli, Appl. Phys. Lett., 67, 3316 (1995).

31. B. H. Erné, D. Vanmaekelbergh, and J. J. Kelly, Adv. Mater., 7, 739 (1995).

32. M. A. Stevens-Kalceff, I. M. Tiginyanu, S. Langa, H. Föll, and H. L. Hartnagel, J. Appl. Phys., 89, 2560 (2001). 